\title{
El motivo literario del cuco (Cuculus canorus) en la literatura europea: análisis y traducción al castellano del Conflictus Veris et Hiemis y el Versus de cuculo (Alcuino de York)
}

\author{
Sergio Guadalajara SalmeróN \\ Universidad Complutense de Madrid, Univesidad de Alcalá/IEMSO \\ sergio.guadalajara@ucm.es
}

\section{INTRODUCCIÓN}

El fin del invierno es un proceso que se desarrolla con sigilo. El avance de la estación primaveral se delata a partir de pequeños detalles que, a medida que se suceden los días, pueden detectarse ya con total claridad: la luz diurna incrementa su duración y el reino vegetal parece volver a la vida. De entre todos los fenómenos naturales que acontecen entonces, quizás la llegada de las aves migrantes sea uno de los más celebrados por el folklore y la literatura, por lo visual y evidente que resulta.

No en vano, las aves han servido al hombre durante milenios para determinar el inicio o final de las estaciones (en muchos casos, para poder ajustar sus actividades agrícolas o económicas a los cambios climáticos). La llegada de las golondrinas (común, Hirundo rustica; dáurica, Cecropis daurica) al continente europeo es probablemente el fenómeno que ha anunciado el inminente inicio de la estación primaveral de forma más frecuente, hecho apreciable ya desde las primeras obras de la literatura griega ${ }^{1}$. Desde luego, es uno de los más notorios de cuantos tienen lugar al final del invierno: los cielos, silenciosos y grises durante meses, ganan en vitalidad con los chillidos y reclamos de golondrinas, aviones y vencejos ${ }^{2}$, que llegan hasta Europa desde África para criar a las nuevas

" A Bárbara y Julia, en esta primavera que comienza. Este trabajo se enmarca en las actividades del proyecto DHuMAR II: From Middle To Golden Age: Translation \& Tradition (Ref.: PY20_00469, Proyecto financiado por la Consejería de Transformación Económica, Industria, Conocimiento y Universidades de la Junta de Andalucía y por FEDER Una manera de hacer Europa).

${ }^{1}$ Es recomendable el trabajo de García Romero (2008), que analiza con detalle los orígenes y usos simbólicos de la paremia «Una golondrina no hace primavera/verano» desde la literatura griega hasta la actualidad. Asimismo, Rodríguez Adrados $(1980,1982)$ se ha ocupado de analizar las distintas versiones que existen de la conocida fábula de la golondrina (y que en otras versiones es protagonizada por la lechuza), que explica por qué algunas especies de aves conviven con el hombre y, al mismo tiempo, otras prefieren mantenerse alejadas.

${ }^{2}$ Menciono de manera conjunta estas tres especies de aves porque las semejanzas etológicas y morfológicas que comparten hacen que, habitualmente, queden asimiladas como un 
generaciones del año ${ }^{3}$. Algo más tardío en su llegada es el cuco $(\mathrm{Cu}$ culus canorus), que hace su aparición en Europa durante los meses de marzo y abril, esto es, cuando la primavera realmente ya ha comenzado a apoderarse de la naturaleza y del paisaje. Este desfase temporal es el que motiva que esta ave, conocida en castellano por los apelativos de cuco, cuclillo, cuquillo o cucliello ${ }^{4}$, sea considerada una genuina emisaria de la primavera. Así es reconocida en la cultura occidental desde la Antigüedad.

Este trabajo se propone analizar y describir la utilización del cuco como símbolo primaveral en dos de las composiciones más conocidas de Alcuino de York ( $c a .732-804)$, dedicadas ambas a esta ave 5 . Se trata del Versus de cuculo y del Conflictus Veris et Hiemis, catalogados como carmina 57 y 58, respectivamente, en la ya veterana edición de Ernst Dümmler ${ }^{6}$. Aunque ofrecen reflexiones e intenciones diferentes, las dos se sirven de un mismo motivo: el cuco convertido en mensajero y catalizador de la primavera. Esta es la razón por la que se analizan conjuntamente ambos poemas, escritos hacia el siglo viII por Alcuino de York (ca. 732-804). Estas composiciones han recibido una cierta atención por parte de la crítica internacional, pero apenas ninguna por parte de la filología española. Asimismo, se ofrece un panorama sintético que explica por qué el autor decidió convertir al cuco en el eje temático fundamental de estos versos, dado que a esta ave se le conceden diversas atribuciones simbólicas en la cultura europea. El segundo núcleo de contenido del artículo está formado por la traducción al castellano del De cuculo y el Conflictus, en tanto que, sorprendentemente, no existe ninguna versión editada en dicha lengua.

mismo animal para quien no posee nociones ornitológicas. Sin embargo, golondrinas y aviones forman parte de la familia de las Hirundinidae, mientras que los vencejos pertenecen a la familia de las Apodidae. Entre ellas, las especies más comunes en España son el avión común (Delichon urbicum), el avión roquero (Ptyonoprogne rupestris), el avión zapador (Riparia riparia), el vencejo común (Apus apus), el vencejo pálido (Apus pallidus) y el vencejo real (Tachymarptis melba).

${ }^{3}$ «Las aves españolas [las golondrinas] invernan en el golfo de Guinea y regresan de forma paulatina al área de cría, con un desfase de hasta tres meses entre el norte y el sur. En Andalucía y Extremadura normalmente empiezan a verse en enero, con llegada masiva desde febrero; en el centro y el este de la Península suelen hacerlo un mes después, y en la Meseta norte y la cornisa cantábrica no se vuelven comunes hasta abril» (SEO/BirdLife, 2020).

${ }^{4}$ Los trabajos de Clavería Nadal (1992) y Bernis (1995: 65-66) analizan en detalle la historia lexicográfica de la voz cuclillo.

${ }^{5}$ Tal y como será examinado más adelante, la crítica no acepta de manera unánime la autoría de Alcuino de York sobre el Conflictus Veris et Hiemis.

${ }^{6}$ Cfr. Dümmler (1881: 269-272). A partir de ahora, me referiré a cada una de estas composiciones mediante las abreviaturas De cuculo y Conflictus, respectivamente. Asimismo, todas las citas de obras grecolatinas se realizan según el sistema clásico y las abreviaturas que constan en la cuarta edición de The Oxford Classical Dictionary (Hornblower et al. 2012). 


\section{EL CUCO EN LA TRADICIÓN LITERARIA EUROPEA}

El cuco es un ave de aspecto inconfundible que, a simple vista, podría parecer el resultado de la fusión de una paloma (Columba palumbus) con un gavilán (Accipiter nisus) ${ }^{7}$. Se trata de un ave muy conocida, aunque esquiva: es difícil de observar, dado que gusta de esconderse entre las frondosas copas de los árboles para poder vigilar los movimientos del resto de pájaros sin ser detectada. Ello tiene que ver con su famosa estrategia reproductora parasitaria, casi única entre las aves europeas ${ }^{8}$ : después de escoger nidos adecuados, la hembra del cuco espera a que alguno sea desatendido por sus progenitores. Entonces, aprovecha la coyuntura para sustituir uno de los huevos originales por el suyo propio. También conocido es su peculiar y alegre canto («cú-cu»), que se escucha con relativa facilidad en la mayor parte del continente europeo entre los meses de abril y julio, especialmente en las cercanías de zonas arboladas.

Todos estos rasgos han hecho del cuco un ave popular en la literatura y cultura europeas durante milenios. Tres son los atributos simbólicos fundamentales que se le han adjudicado en la tradición: es considerado mensajero de la primavera, puede ejercer una función oracular o, también, puede ser utilizado como metáfora del adulterio, la burla y el engaño. Todas estas atribuciones son perfectamente compatibles entre sí y, de hecho, coexisten en los ámbitos popular y literario. En cualquier caso, es claro que el cuco posee una naturaleza ambigua: en algunas ocasiones, positiva; en otras, negativa. La bibliografía dedicada a analizar el simbolismo del cuco es amplísima, en especial en el ámbito de las tradiciones populares $^{9}$. Si bien el propósito de este artículo no consiste en examinar

${ }^{7}$ Desde la Antigüedad existen leyendas que afirman que el cuco desaparece durante el otoño y el invierno, justamente, porque se transforma en gavilán. El propio Aristóteles reflexiona sobre esta posibilidad (Arist. Hist. an. VI. 563b. 15; Pallí Bonet 1992: 321-322). Plinio el Viejo considera que el cuco nace del gavilán y que adquiere su propia forma durante la primavera: «Coccyx videtur ex accipitre fieri, tempore auni figuram mutans, quoniam tunc non apparent reliqui nisi perquam paucis diebus [...]» (Plin. HN. X. 11, 25); «Parece que el cuclillo nace del halcón y cambia su forma en una determinada época del año, pues justo entonces los demás halcones sólo aparecen muy pocos días [...]» (Barrio Sanz et al. 2003: 364) [la traducción de accipitre por 'halcón' no es exacta, ya que estas especies pertenecen a géneros diferentes: Accipiter y Falco; son los gavilanes, azores y milanos las especies que se ajustan con exactitud al término original latino]. De hecho, Plinio el Viejo clasifica al cuco en la familia de las aves rapaces por este motivo. La tradición oral moderna también se refiere a esta relación entre el cuco y el gavilán: «En Mieres se cree que el cuco - sin duda por su parecido con el gavilán- se transforma por el invierno en ave rapaz» (Pérez de Castro 1974: 195). Sobre la historia de la confusión entre estas dos aves en la literatura clásica, vid. Normand (2015: 187-188).

${ }^{8}$ Tan solo el críalo (Clamator glandarius), otro miembro de la familia de los cucos o $\mathrm{cu}$ culidae, se reproduce por nidoparasitismo en Europa. El críalo está especializado en depositar sus huevos en nidos de córvidos (fundamentalmente, de urracas, Pica pica), mientras que el cuco suele optar por nidos de acentores comunes (Prunella modularis), carriceros comunes (Acrocephalus scirpaceus) o petirrojos (Erithacus rubecula).

${ }^{9}$ Remito a los trabajos que Pedrosa $(2001,2010)$ ha dedicado a documentar todas estas tradiciones populares. Ineludible resulta, asimismo, el capítulo que Armstrong (1958: «Chapter 
desde una perspectiva diacrónica la evolución de los diferentes significados alegóricos asociados al cuco, sí resulta pertinente realizar una síntesis general que permita comprender el lugar que ocupan las composiciones de Alcuino de York en el marco de todas estas tradiciones.

En el folklore, esta ave se ha convertido en fuente de predicciones y vaticinios absolutamente variados. Sin ir más lejos, en la España rural han sido frecuentes algunas costumbres como preguntar al cuco, cuando es detectado en las cercanías, por los años restantes de vida (o también por los años o meses que faltan para contraer matrimonio). El número de reclamos emitidos tras realizar la consulta son tomados como respuesta definitiva. Similares procedimientos se han documentado en lugares como Gran Bretaña, Francia o República Checa (en esta última zona se cree, además, que puede predecir el número de hijos que tendrá una pareja) ${ }^{10}$.

Frecuente es también la asociación del cuco con la burla, el adulterio, la traición o el engaño. Este es el sentido que adquiere la voz cuculus (cuco) en la comedia Asinaria de Plauto, en la que se emplea en dos ocasiones para hacer referencia a Deméneto, que es infiel a su esposa Artemona en un lupanar (Plaut. Asin. 922-923; 934) ${ }^{11}$. Dicha significación sigue vigente en la actualidad en las voces cuckold (inglés) o cocu (francés), que pueden traducirse como 'cornudo'. En castellano tal acepción se ha conservado en el término cuclillo, significado que fue recogido por Gonzalo Correas en su Vocabulario de refranes: «Cucú, guarda no lo seas tú. «Cucú» es la voz y canto del cuclillo repetida, y tiénela el vulgo tomada por cornudo, y para notar dello a uno dicen «cucú», por lo que alude a «cuerno», que es su comienzo» (Combet 2000: 210) ${ }^{12}$. Esta asociación semántica se explica, en cualquier caso, a partir del aludido comportamiento reproductor parasitario del cuco, que deposita sus huevos en nidos ajenos para que sean criados por otros

12. The Harbinger of Spring. The Cuckoo») dedica a examinar de forma completa la simbología del cuco en su ya clásica obra (cito por la versión electrónica del libro, carente de paginación).

${ }^{10}$ Cfr. Armstrong (1958: «Chapter 12. The Harbinger of Spring. The Cuckoo»).

${ }^{11}$ «No, muerto no, sino, no lo niegues, el más sinvergüenza de todos los mortales. Pero todavía sigue sin moverse, el cuco este. ¡Arriba, enamorado, a casita!» (Plaut. Asin. 922-923); « ¿Cuco!, ¿con esa cabeza llena de canas tiene que venir tu mujer a sacarte de una casa de perdición?» (Plaut. Asin. 934). Cfr. González-Haba (1992).

12 Otro refrán recogido por Correas insiste en la misma idea: «Por mi canto el cluquillo [sic]. Por el juez cantó el cluquillo [sic]. Iban dos caminando, y cada uno tenía al otro por cornudo. Oyeron cantar el cucú, y dijeron uno a otro: «Por vos cantó. - No, sino por vos». Agraviados ambos fueron a querellarse, y el juez, vista su locura y porfía, dejólos gastar, y al cabo sentenció que por él cantó, por lo que le valió, y ansí es el refrán todo: «Por vos cantó el cuclillo. - No cantó sino por vos. - No, sino por vos. - Que ni por vos ni por vos, sino por mí cantó». Dicen que el cuco no hace nido, sino que en los de otras aves come los güevos y pone los suyos, y ansí se los crían, y parece con esto que las encornuda; de aquí tiene el vulgo al canto del cuclillo por nota de cornudo, y motejan diciendo: «cuco», «cucú». No creo la historia, por ser contra la naturaleza de los animales, que aman sus hijos [...]» (Combet 2000: 650). 
pajarillos ${ }^{13}$. La tradición hispánica también ha desarrollado esta misma asociación simbólica en multitud de refranes y canciones ${ }^{14}$, tal y como atestiguan dos composiciones del Cancionero de Baena ${ }^{15}$. Otro de los testimonios literarios más conocidas que forma parte de estas corrientes es el que compuso Juan del Encina (1468-1529) a partir del mismo refrán que recoge Correas. Se encuentra en el Cancionero Musical de Palacio $(C M P, 94)$ con el título de «¡Cucú, cucú, cucucú!» ${ }^{16}$ :

\author{
¡Cucú, cucú, cucucú! \\ Guarda no lo sea tú. \\ Compadre, debes saber \\ que la más buena mujer \\ rabia siempre por [h]oder. \\ Harta bien la tuya tú. \\ Compadre, has de guardar \\ para nunca encornudar; \\ si tu mujer sale a mear, \\ sal junto con ella tú.
}

(González Cuenca 1996: 75)

Sin duda, este rico caudal de tradiciones ha sido fundamental en la cultura europea durante siglos. Sin embargo, los usos simbólicos del cuco de los que se sirve Alcuino de York no tienen que ver con estas dos últimas corrientes que acaban de ser descritas (la burla y el adulterio), sino con la asociación del ave con la llegada de la estación primaveral (si bien en el caso del De cuculo sí existen interferencias con estas connotaciones más negativas). Así, a finales del invierno el mundo rural europeo aguarda al cuco con impaciencia. Cuando por fin retorna, desencadena la mayor de las alegrías, pues significa que el tiempo del frío ya está próximo a declinar. Es este un momento crucial para el desarrollo de las cosechas y cultivos: en la península ibérica suele producirse durante los últimos días de marzo y los primeros de abril. Tal y como ha analizado José Manuel Pedrosa, el refranero es especialmente rico en referencias a este periodo:

${ }^{13}$ Para una historia y análisis de las tradiciones asociadas al cuco, el adulterio y las infidelidades, vid. Vaz da Silva (2006).

${ }^{14}$ Vid. Pedrosa (2010: 34).

${ }^{15}$ «[...] Sandío, mal consejado, / persona mal consejada, / la que tienes olvidada / sé que tiene a ti olvidado / por ante cuco provado» (Cancionero de Baena, 184, vv. 14-18); «Señor Juan Alfonso, por más que suplique / el çiego cucrillo, garçón de Sevilla, / con sus ojos turvios e falsa neguilla, / [...]» (Cancionero de Baena, 362, vv. 1-3). Vid. Dutton/González Cuenca (1993: 209, 641).

${ }^{16}$ La composición 101 del Cancionero musical de Palacio (CMP) utiliza el mismo refrán que el que aparece en la número 94, aunque modifica la copla: « ‘Cucú, cucú, cucucú! / Guarda no lo seas tú. / Compadre, guárdate del cuerno / en verano y en invierno, / que, aunque te parezca tierno, / duro le hallarás tú» $(C M P, 101)$. Asimismo, asocia al cuco con el periodo temporal en que se produce el paso del invierno a la primavera. Vid. González Cuenca (1996: 78). Agradezco la referencia al profesor Ángel Gómez Moreno. 
El refranero románico (y el europeo en general) insiste una y otra vez en asociar el cuco con la frontera que separa los últimos días del mes de marzo y los primeros del mes de abril. Frontera que coincide, seguramente, con el periodo más interesante y más simbólicamente marcado del calendario folclórico europeo. Son innumerables, en efecto, las paremias, las creencias, las supersticiones, las leyendas relativas a ese período, que suele ser visto como inquietante, crítico, por lo general incluso nefasto, para el campesino, para sus campos y para sus ganados [...]. (Pedrosa 2010: 37)

La ciencia respalda este temor ancestral con datos objetivos: durante el otoño, las plantas preparan su organismo para poder soportar la crudeza del invierno. En su interior se desencadenan diversos mecanismos biológicos que les permiten no sufrir daños por el hielo (entre otros, resulta significativo el aumento de la proporción de azúcares que se produce en el interior de las células, lo que reduce su punto de congelación). Sin embargo, la cambiante climatología que es propia de los días próximos al equinoccio de primavera puede provocar heladas, precisamente, cuando los organismos vegetales se han despojado ya de su protección invernal y, por lo tanto, son completamente vulnerables a sus consecuencias: ello explica la devastación que provocan las repentinas bajadas de temperatura de abril en árboles y cultivos ${ }^{17}$.

Así, tras esta breve incursión en la ciencia biológica, se entiende mejor la alegría que produce la llegada del cuco a tierras europeas, en tanto que implica que las temidas heladas serán ya improbables. Las dos composiciones de Alcuino de York, el De cuculo y el Conflictus, no son más que la realización literaria de ese regocijo. Por ello, no debe sorprender la alta recurrencia que presenta el adjetivo laetus $(-a,-u m)$ en el plano literario, especialmente en el texto del Conflictus ${ }^{18}$. Según Ernout y Meillet (2001: $s$. v. laetus, $-a$, -um), además de expresar felicidad, dicho término se utilizaba en la variedad rústica de la lengua latina para ponderar la abundancia y la fertilidad de la tierra o de sus productos derivados. Al mismo tiempo, en el ámbito augural, el sintagma laetum augurium también hacía referencia a un vaticinio que prometía abundancia o prosperidad. Es claro, por lo tanto, que el uso de este adjetivo por parte de Alcuino de York entronca y se explica a partir de ambos usos lingüísticos.

${ }^{17}$ El profesor David G. Haskell explica estos procesos con exactitud: «Las plantas empiezan a prepararse varias semanas antes de las primeras heladas. Trasladan el ADN y otras estructuras delicadas al centro de las células y después las envuelven para protegerlas. Las células se vuelven más grasas, y los enlaces químicos de estas grasas cambian de forma para hacerlas fluidas en condiciones de frío. Las membranas en torno a las células se vuelven permeables y flexibles. Una vez transformadas, las células quedan acolchadas y elásticas, capaces de absorber la violencia del hielo sin sufrir daños. [...] Una helada fuera de temporada mata ramas que, cuando están bien aclimatadas, pueden aguantar las noches más frías del año» (Haskell 2019: 45).

${ }^{18}$ Dicho adjetivo se emplea en seis ocasiones en el Conflictus: «Laetas Camenas; cum germine laeto; convivia laeta; laetos agros; laeta videntur; germina laeta» (vv. 3, 16, 25, 30, 31, 47). 
Las tradiciones que celebran cada año la llegada del cuco a Europa son muy numerosas, tal y como se ha ocupado de documentar por extenso la crítica. Citaré tan solo algunos ejemplos significativos que permiten comprobarlo. El 1 de abril se festeja en Escocia el Gowk's Day (en el dialecto del inglés hablado en Escocia, Gowk es el término que designa al cuco $^{19}$ ), equivalente al célebre April's Fool's Day ${ }^{20}$. Dicha efeméride celebra la llegada la primavera a partir de la fecha de retorno del cuco, que al norte de las islas británicas tiene lugar durante las dos primeras semanas del mes de abril. Es evidente el protagonismo que adquiere esta ave precisamente en una festividad asociada a la primavera. Asimismo, es posible comprobar en los estudios antes citados la existencia de infinidad de cancioncillas y refranes en todo el continente europeo que se refieren al cuco como símbolo primaveral. Por ejemplo, en la tradición castellana: «Cuando el cuco llega, entonces es primavera; si el cuco aún no llegó, es que la primavera no comenzó»; «Entre marzo y abril, sale el cuco de su cubil; con la nieve no quiere venir» (Pedrosa 2010: 36).

No solo las tradiciones populares han considerado al cuco como heraldo de la primavera, pues no son escasas las obras de la literatura clásica que le han reconocido esta misma función simbólica. Ya en los Trabajos y días, una de las primeras obras de la literatura universal, Hesíodo describe la llegada del cuco como símbolo inequívocamente primaveral (Hes. $O p$. 485-489). De hecho, sirve para establecer una señal nítida a la que el agricultor debe atender para iniciar las labores propias de este tiempo:

Si te retrasas en arar, este puede ser tu remedio: cuando el cuclillo cante por primera vez entre las hojas de la encina y alegre a los hombres sobre la tierra sin límites, entonces ruega a Zeus que haga llover al tercer día y no pare hasta que el agua ni sobrepase la pezuña del buey que quede por debajo. De este modo, el que ara tarde puede obtener iguales resultados que el que ara pronto. Guarda bien todos mis consejos en tu corazón y que no te pase inadvertida la llegada de la blanca primavera ni la estación de las lluvias (Pérez Jiménez/ Martínez Díez 1978: 149).

${ }^{19}$ La voz que hace referencia al cuco en inglés medio es goke, gowke, que deriva del nórdico antiguo gauk. En inglés antiguo existía la voz gēac, y en alto alemán antiguo, gouh. La huella etimológica es asimismo detectable en los nombres actuales de esta ave en danés $(G ø g)$, islandés (Gaukur), noruego (Gjøg) o sueco (Gök), dado que todas estas lenguas proceden del nórdico antiguo. En cualquier caso, el término gowk posee dos acepciones en el inglés de Escocia: 'cuco', pero también 'tonto, torpe, embobado' (Merriam-Webster 2020, s. v. Gowk). De este modo, el Gowk's Day no deja de ser una construcción lingüística pretendidamente polisémica.

${ }^{20}$ El April's Fool's Day ('Día de las bromas de abril') es una festividad propia, entre otras, de las culturas anglosajona, francesa (Poisson d'avril) o italiana (Pesce d'aprile). Es parejo al Día de los Santos Inocentes que se celebra en España e Hispanoamérica el 28 de diciembre, pues ambas efemérides están dedicadas a realizar diferentes tipos de bromas. 
De igual manera, Aristófanes ofrece en Las aves ${ }^{21}$ un testimonio adicional en el que el canto del cuco es tomado como referencia para el calendario de siega, pero que, al mismo tiempo, adquiere parte de las connotaciones sexuales que también se le atribuyen en el ámbito folklórico (Ar. Av. 504-507) 22 :

Pistetero: - Y el cuclillo era rey de Egipto y de toda Fenicia, y cuando el cuclillo decía «¡cucú!», todos los fenicios segaban en los campos el trigo y la cebada.

Evélpides: —Esa es, entonces, la razón del dicho « ¡Cucú, capullos al campo!» (Macía Aparicio 2007: 381).

Todos los tratados de naturaleza de la literatura clásica reafirman el carácter primaveral del cuco. Además de las ya citadas obras de Aristóteles o Plinio el Viejo, también Claudio Eliano informa de que esta ave es vista únicamente entre el inicio de la primavera y mediados de julio ${ }^{23}$. Relevante es la descripción que realiza el geógrafo e historiador Pausanias (s. II d. C.) en su célebre Descripción de Grecia de una escultura que representaba a la diosa Hera, que estaba situada en las cercanías del Hereo de Micenas (Paus. II. 17. 4). Permite comprender el sentido de otra de las tradiciones ligadas a esta ave:

La imagen de Hera está sentada en un trono, es de gran tamaño, de oro y marfil, y obra de Policleto; encima tiene una corona con las Cárites y las Horas labradas, y en una mano lleva una granada y en la otra un cetro. Voy a dejar de lado lo relativo a la granada - pues es una historia de la que no se puede hablar-. En cuanto al cuco que está sentado en el cetro, lo explican diciendo que Zeus, estando enamorado de Hera cuando era virgen, se transformó en este pájaro, y que ella lo cazó como juguete. Esta leyenda y todas las cosas semejantes que se dicen acerca de los dioses las refiero aunque no las acepto, pero, sin embargo, las escribo (Herrero Ingelmo 1994: 258).

${ }^{21}$ La propia ciudad que en la obra fundan Pistetero y Evélpides hace referencia al cuco en

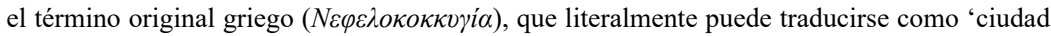
de los cucos y las nubes'. La edición española traduce el nombre como 'Piopío de las Nubes' (Macía Aparicio 2007: 330). Por su parte, la versión inglesa se ha mantenido más apegada al sentido original del nombre, que traduce como 'Cloud-Cuckoo Land'. Tal fortuna ha conocido que, incluso, se utiliza como expresión en la lengua inglesa para hacer referencia a un estado de fantasía desmedidamente optimista y del todo fantasioso. Vid. Mynott (2018: 12).

${ }^{22} \mathrm{Tal}$ y como explica en nota el editor del texto, Luis Miguel Macía Aparicio, «campo y cebada son expresiones eufemísticas del sexo de mujeres y hombres. Evélpides, que en esta escena interpreta todas las palabras de Pistetero en un sentido muy concreto e inmediato, las toma de esa manera y cita el proverbio manteniendo «campo» pero cambiando «cebada» por «glande», de ahí nuestro «capullos»» (Macía Aparicio 2007: 381).

${ }^{23} \mathrm{Cfr}$. Ael. NA. III, 30. El resto de referencias antiguas ya han sido citadas en la nota 7 . 
En efecto, el cuco está asociado a Hera desde que Zeus se metamorfoseó en esta ave para poder acercarse a ella y violarla ${ }^{24}$. Por ello, son habituales las representaciones iconográficas que muestran a esta diosa sosteniendo entre sus manos un cetro coronado por un cuco.

Ya en la Edad Media, Isidoro de Sevilla se refirió al cuco en las Etimologías, aunque se limita a consignar su condición de ave migratoria (asegura, además, que el cuco realiza dicho viaje anual encaramado a la espalda de los milanos) $)^{25}$. Tanto Angelo de Gubernatis como Edward A. Armstrong muestran ejemplos literarios en los que el cuco es asociado a la primavera en las culturas europeas y orientales más allá del periodo antiguo $^{26}$. Por supuesto, existen ejemplos de estas tradiciones en la literatura medieval castellana: el Marqués de Santillana también se sirve del cuco como motivo central en el poema «Por un valle deleytoso $[\ldots] \gg »^{27}$. En él, se menciona directamente el ave ( «Cuco me llaman por mi nombre», v. 17) y se describe un ambiente que, si bien no es reconocido explícitamente como primaveral, sí lo es de forma implícita, en tanto que se trata de un perfecto locus amoenus. La novedad de esta composición reside, sin embargo, en que reúne dos de los principales usos alegóricos del cuco que han sido analizados con anterioridad: es símbolo de la primavera, pero también es asociado con la burla («este trahe en su devisa / mucha gente de cucaña», vv. 7-8) y la infidelidad conyugal («Señor, dixe, vuestro canto / en otro tiempo me ponía / en temor e grand espanto / por una señora mía», vv. 25-28).

Es sencillo comprobar cómo esta simbología asociada al cuco se extiende más allá de la Antigüedad o la Edad Media. Así, poetas ingleses como William Shakespeare (1564-1616), Edmund Spencer (ca. 1552-1599) o William Wordsworth (1770-1850) también se refieren a él como mensajero de la primavera ${ }^{28}$. Conviene analizar la utilización que

${ }^{24}$ De nuevo, Pausanias informa en la Descripción de Grecia (Paus. II. 36. 1) de que esta transformación de Zeus en cuco tuvo lugar en el monte Tórnax, accidente geográfico que luego cambiaría su nombre por «Monte del cuco» precisamente por este motivo.

25 «Tucos, quos Hispani ciculos vocant, a voce propria nominatos. Hi veniendi habent tempus, milvorum scapulis suscepti propter breves et parvos volatus, ne per longa aeris spatia fatigati deficiant. Horum salivae cicadas gignunt» (Isid. Etym. XII. 7, 67); «Los tuci (cuclillos), llamados ciculi por los españoles, reciben su nombre por la voz que emiten. Cuando llega la época de la migración, se montan sobre las espaldas de los milanos, pues su vuelo es corto y para evitar caer en tierra fatigados por los largos trayectos que deben recorrer. De su saliva nacen las cigarras»». Cfr. Oroz Reta/Casquero (2004: 950-951). Isidoro de Sevilla se refiere a los milanos negros (Milvus migrans), especie estival en Europa que inverna a África.

${ }^{26}$ Vid. Armstrong (1958, «Chapter 12, The Harbinger of Spring. The Cuckoo») y Gubernatis (2002: 56,58$)$.

${ }^{27}$ Cito por la edición de Ángel Gómez Moreno y Maxim P. A. M. Kerkhof (1988: 80-81). Esta es la primera estrofa: «Por un valle deleytoso, / do mora gentil conpaña, / oý un canto sabroso / de un ave muy estraña. / Bien vos digo que en España / non vi otra de tal guisa: / esta trahe en su devisa/ mucha gente de cucaña». Agradezco la referencia al profesor Gómez Moreno.

${ }^{28}$ Cfr. Armstrong (1958: «Chapter 12, The Harbinger of Spring. The Cuckoo») y Abella (2017: 119). 
Shakespeare hace de esta ave en la temprana comedia Love's Labour's Lost (Afanes de amor en vano), compuesta hacia 1595. La última escena de la obra es un diálogo en el que se alaba a dos aves: el cuco y el búho. Curiosamente, los contendientes son los personajes alegóricos de Primavera e Invierno, cuyos nombres son citados en latín (Ver, Hiems). Cada uno de ellos describe escenas propias de su estación y, aunque no existen correspondencias exactas con el texto del Conflictus, lo cierto es que el tono, el ritmo y el contenido son muy similares a aquel. En el fragmento final de Love's Labour's Lost, el cuco no es presentado como catalizador de la primavera, sino como una de las muchas manifestaciones que son propias de esta estación (y es reconocido, además, como símbolo del marido cornudo).

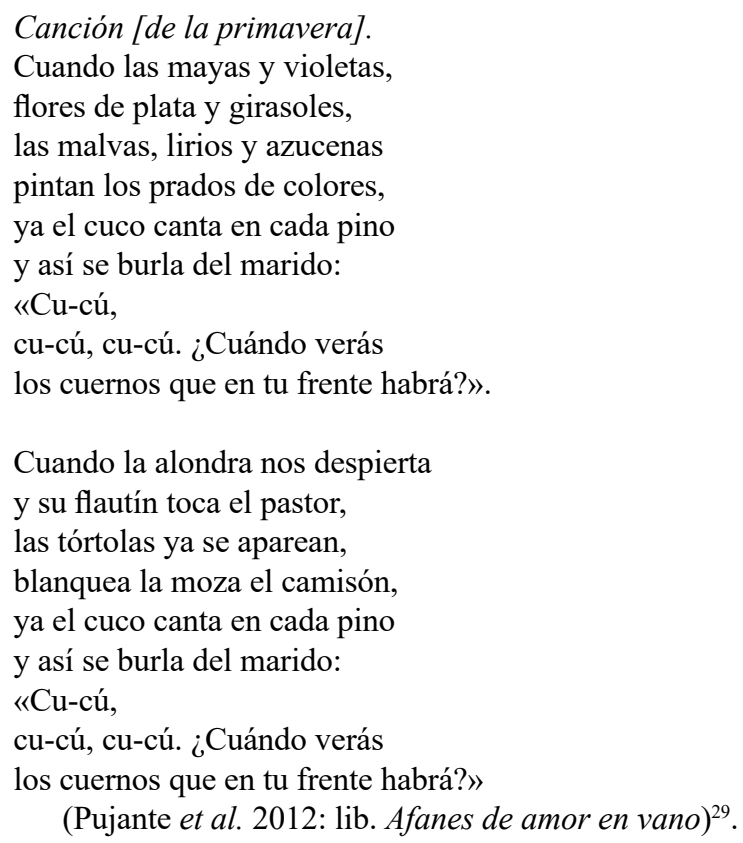

La composición de Shakespeare coincide con el texto del Conflictus en la descripción que ambos fragentos realizan de los campos que estallan de colorido. En concreto, el verso «Collibus in nostris erumpant germina laeta» del Conflictus (v. 47) parece evocarse en el comienzo de la canción que entona Primavera, que describe las muchas especies de flores que comienzan a adornar los prados (la idea se repite, asimismo, en el verso 28 del Conflictus; "Ore feret flores cuculus [...]»). El empleo de los nombres latinos de ambos personajes sin que exista una razón que lo justifique, la descripción de la escena como un diálogo o

\footnotetext{
${ }^{29}$ El diálogo completo se ubica entre los versos 901-936 de la obra.
} 
contienda verbal, la propia mención del cuco y la descripción de los prados coloreados por las flores podrían sugerir que, tal vez, Shakespeare pudo haber conocido el texto del Conflictus -directa o indirectamente-e inspirarse de forma parcial en él. Desde luego, esta no es más que una hipótesis que requiere de nuevas investigaciones para comprobar su validez, puesto que también es posible que Shakespeare se limitase a reunir en su obra las significaciones simbólicas que se le atribuían al cuco durante la Edad Media y el Renacimiento ${ }^{30}$.

El análisis de los atributos simbólicos que ha recibido el cuco a lo largo de los siglos podría componer, por sí mismo, un estudio de amplísima extensión. En cualquier caso, son evidentes las conexiones que existen entre esta ave y la primavera desde la Antigüedad hasta nuestros días ${ }^{31}$. Los poemas que Alcuino de York le dedicó se adscriben, sin duda, a esta tradición.

\section{El Versus de CUCULO Y el CONFLICTUS VeRIS ET HIEMIS: DOS POEMAS DEDICADOS AL CUCO}

Alcuino de York fue un gran conocedor y admirador de la obra de Virgilio (70-19 a. C.). Tanto es así que escribió algunas de sus propias composiciones a partir del contenido, estilo y estructura de las églogas virgilianas. Es el caso de los dos poemas que competen a este trabajo, en los que resuenan con fuerza los ecos de estas tradiciones bucólicas. La autoría de Alcuino respecto al De cuculo no ha sido nunca cuestionada ${ }^{32}$; sin embargo, dicho consenso no existe en torno al Conflictus: la crítica ha debatido con insistencia desde el siglo XIX sobre la identidad de su autor. Si bien no es el objetivo de este artículo añadir nueva información al respecto, sí es necesario hacer referencia a las principales teorías existentes, recogidas por Castillo (1973: 53-54) y ampliadas recientemente por Zogg (2017: 125-127): tanto Dümmler (1881: 269-270) como

${ }^{30}$ Por lo tanto, es necesario realizar un trabajo de investigación monográfico sobre las fuentes que pueden explicar el origen de las referencias al cuco en la obra de Shakespeare: ello excede, con mucho, el propósito y tema de este artículo. Al respecto, es posible que existan puntos de unión entre William Shakespeare, Geoffrey Chaucer (ca. 1342-1400) y sir John Clanvowe (siglo XIv). Ambos autores medievales escribieron composiciones literarias que otorgan un papel relevante a esta ave en un ambiente plagado de referencias al amor y la primavera. En concreto, se trata del poema Parlement of Foules (El parlamento de las aves) de Chaucer y del debate poético de Clanvowe, The Cuckoo and the Nightingale (El cuco y el ruiseñor). En el caso de la obra de Clanvowe, al cuco se le atribuyen connotaciones negativas propias de la tradición (como la deslealtad o la impiedad). Agradezco las referencias al anónimo revisor de este artículo.

${ }^{31}$ Un último ejemplo muestra la vigencia de estas tradiciones. Los compositores Imanol y Paco Ibáñez han dedicado una de sus canciones precisamente a ello, titulada Kukua eta primadera (El cuco y la primavera; Oroitzen, 1999). La composición desarrolla el motivo del cuco como heraldo primaveral.

${ }^{32}$ La aceptan todos los estudiosos que han analizado el poema: Dümmler (1881: 269-270), Carrara (1909: 44-45) y Dale Scott (1965). 
McEnerney (1981) consideran que el poema fue escrito por Alcuino de York, mientras que Castillo (1973: 60-61) supone más probable que el autor fuese uno de sus discípulos, lo que explicaría la presencia de algunos de los errores gramaticales presentes en el texto. Zogg (2017: 127), por su parte, parece aceptar el punto de vista de Raby (1957: 208), que considera que no existen pruebas seguras sobre la autoría de Alcuino, por lo que prefiere no decantarse por ninguna de las dos propuestas.

Son varios los trabajos que se han ocupado de examinar en detalle ambos poemas, en especial desde el punto de vista simbólico, ecdótico y filológico ${ }^{33}$. Esta es la razón por la que mi análisis se centrará exclusivamente en el estudio del motivo alegórico del cuco en las dos composiciones. Prestaré atención al modo en que este símbolo ornitológico se inserta en las tradiciones explicadas con anterioridad, así como a la estrecha relación que existe entre el contenido poético y la propia realidad que le sirve como referencia. A pesar de su trascendencia, este aspecto no ha recibido hasta la fecha más que una atención somera. De hecho, la utilización de esta ave en el plano literario no es en absoluto aleatoria; al contrario, es fundamental para comprender el sentido de los dos poemas. Así, aunque el artículo que Carmen Castillo dedicó al Conflictus es excelente y completo, existe una imprecisión en él que debe ser enmendada, en tanto que afecta a la exégesis de ambas composiciones. No es otra que la valoración que se dedica al cuco como motivo poético:

Otra novedad respecto de la tradición literaria latina es la presencia del cuclillo como símbolo de la primavera: más que de alabanza, en el mundo latino el cuclillo es un término de burla o desprecio. [...] No es el cuclillo, sino el ruiseñor el ave que representa la primavera en los países mediterráneos, y son elogios al ruiseñor lo que la tradición latina conoce (Castillo 1973: 57).

En efecto, el anterior apartado ha mostrado cómo el cuco ha sido empleado ya desde la Antigüedad como símbolo de engaño, escarnio o adulterio en el ámbito literario. Sin embargo, también ha quedado claro que esta no es más que una de las múltiples ramificaciones que existen en las tradiciones asociadas a esta ave. Por el contrario, los textos griegos y latinos en los que el cuco ejerce la función de heraldo de la primavera son notablemente más frecuentes y usuales que el resto de los usos simbólicos referidos previamente: Hesíodo, Aristófanes, Aristóteles o Claudio Eliano son solo algunos de los autores más conocidos que describieron la unión existente entre la estación primaveral y el cuco. Este hecho es perceptible en los textos medievales e, incluso, en composiciones cultas o populares contemporáneas, tal y como ha sido analizado

${ }^{33}$ Buena parte de ellos ya han sido citados. Sobre el Conflictus, vid. Castillo (1973) y Zogg (2017). Sobre el De cuculo, vid. Dümmler (1879), Bulst (1955) y, especialmente, Scott (1965). 
en las líneas iniciales de este trabajo. En cuanto al ruiseñor (Luscinia megarhynchos), es evidente que es una de las aves asociadas de forma inequívoca a la primavera en la tradición occidental. Sin embargo, el ruiseñor no desempeña en esta de manera exclusiva el papel de mensajero de la primavera: específicamente, el ruiseñor es un ave que representa el amor y el disfrute sexual en la tradición literaria (y está unida, además, al espacio de un perfecto locus amoenus ${ }^{34}$ ). La relación de esta ave con la primavera es circunstancial; en realidad, son la golondrina y el cuco las aves que anuncian el inicio de la alegre estación de manera absolutamente mayoritaria ${ }^{35}$. En suma: el ruiseñor no advierte de la llegada de la primavera, sino que la adorna con los bellos cantos que destina a la seducción amorosa ${ }^{36}$.

Por todo ello, es claro que este uso alegórico del cuco no supone ninguna novedad en el ámbito de la tradición literaria latina. Al contrario, se trata de un elemento evidente de continuidad respecto de aquella. Alcuino de York no parte de la nada cuando decide construir el simbolismo de la composición en torno al cuco, sino que se adscribe pretendidamente a una de las corrientes alegóricas más populares que se relacionan con

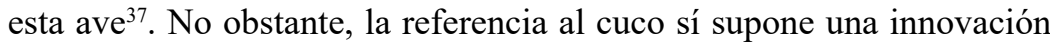
respecto de la poética de Virgilio, autor que no alude al cuco como símbolo primaveral en ninguna de las églogas de las Bucólicas.

El Conflictus Veris et Hiemis es un debate compuesto por cincuenta y cinco hexámetros latinos en el que se detectan constantes reminiscencias del universo bucólico virgiliano. Ello puede comprobarse de forma inmediata en el nombre de los personajes, pero también en el contenido

${ }^{34}$ El ruiseñor, de hecho, suele simbolizar al galán tentador o al hombre enamorado en la lírica europea. Es muy conocido el uso alegórico que Francesco Petrarca realiza del ruiseñor en el Fragmento CCCXI, con el que se identifica por cantar dulces lamentos durante noches completas. Para una breve síntesis de las significaciones que puede adquirir el ruiseñor en el ámbito literario, vid. Guadalajara Salmerón (2020: s. v. ruiseñoles). Para un examen de su influencia en la lírica áurea, vid. Lida de Malkiel (1975: 100-117).

${ }^{35}$ «The swallow is probably the commonest spring marker for the ancients. Sappho does also nominate the nightingale in one surviving fragment about 'the messenger of spring, sweetvoiced nightingale', but it was the swallow that gained proverbial status [...]»; «[La golondrina es probablemente el símbolo más común de la primavera para los antiguos. Safo también nombra al ruiseñor en un fragmento que se conserva sobre «el mensajero de la primavera, el ruiseñor de voz dulce», pero fue la golondrina la que adquirió el carácter proverbial] [...]» (Mynott 2018: 14).

${ }^{36}$ Un ejemplo prototípico de la significación simbólica que adquiere habitualmente el ruiseñor en el ámbito literario aparece en los cinco primeros versos del romance Fontefrida: «Fonte Frida, Fonte Frida, / Fonte frida y con amor, // do todas las avecicas / van tomar consolación // si no es la tortolica / qu'está viuda y con dolor. // Por allí fuera pasar / el traidor del ruiseñor; // las palabras que le dice / llenas son de traición // [...]» (Díaz-Mas 1994: 311).

${ }^{37}$ Las aves también son utilizadas como símbolos poéticos por Alcuino de York en otras composiciones. Sirvan como ejemplo el cisne (Cygnus olor) y el ruiseñor (Luscinia megarhynchos), elementos alegóricos de importancia en los Carmina 60 (Dümmler 1881: 273-274) y 61 (Dümmler 1881: 274-275), respectivamente. Sobre el poema dedicado al ruiseñor, vid. Kim (1992). 
y estructura tripartita del poema ${ }^{38}$. La introducción (vv. 1-9) presenta a Dafnis y Palemón, que forman parte de un grupo de pastores reunido al comienzo de la estación primaveral para cantar alabanzas al cuco. El núcleo de la composición (vv. 10-42), sin embargo, está compuesto por el debate que mantienen los personajes alegóricos de Primavera e Invierno (Ver, Hiems), que, de forma alterna (y en estrofas de tres versos), defienden o atacan al cuco por ser quien da inicio a los cambios inherentes a la estación primaveral: las resonancias e influencia del canto amebeo son más que evidentes $\mathrm{y}$, de nuevo, suponen un fuerte punto de unión con la poética virgiliana ${ }^{39}$. A modo de cierre (vv. 43-55), los pastores reunidos, encabezados de nuevo por Dafnis y Palemón, otorgan la esperada victoria a Primavera y celebran con entusiasmo al cuco, al que solicitan su próxima llegada. Es, en definitiva, una alegre conmemoración de la primavera que ofrece una perspectiva muy favorable del cuco, por lo que se aleja por completo de aquellas corrientes de la tradición que adjudican a esta ave connotaciones más negativas (como la traición o el adulterio).

La descripción que se realiza del cuco en el Conflictus no es particularmente prolija: de entre todos los rasgos morfológicos que lo identifican, el poeta fija su atención en su pico brillante, que le permite emitir su canto característico $^{40}$. Es esta una circunstancia del todo original, dado que no se trata del atributo más destacado del aspecto del cuco en comparación con otras aves. En este sentido, la tradición, además de en su conocido reclamo, suele fijarse en su plumaje gris barrado, elemento que otorga al cuco una forma mixta entre el gavilán y la paloma. Así, que el poeta opte por destacar la apariencia del pico evidencia que era un buen conocedor de esta ave: el pico del cuco es de color amarillo en la base, pero posee un tono metálico brillante en el resto de su extensión. Describir estos pequeños matices solo le es posible a quien posee un conocimiento preciso de sus rasgos a partir de su observación directa en la realidad.

Es importante detallar cómo la etología y fenología del cuco permiten explicar de manera completa el significado del Conflictus: su mención va más allá del uso de un antiguo motivo literario. Tanto es así que la naturaleza migratoria del ave se convierte en un elemento fundamental para la comprensión del poema. Según el sentido lírico de la pieza, el cuco es el agente responsable de la llegada del buen tiempo y, por lo tanto, de los cambios a él asociados: se trata de una bella imagen para

${ }^{38}$ El nombre de los personajes de estas dos composiciones (Dafnis, Palemón, Menalcas) es tan solo otro de los elementos que evidencia la inserción de ambos poemas en la corriente bucólica virgiliana. Los ya citados trabajos de Dümmler (1881: 270-272), Castillo (1973: 5657) y Zogg (2017: 128-137) analizan con exhaustividad los loci comunes que existen entre el Conflictus y las obras de algunos autores clásicos (Virgilio, Horacio u Ovidio), por lo que remito a su lectura para más detalles.

${ }^{39}$ Para un estudio de la influencia del canto amebeo en la literatura castellana, vid. Escudero Martínez (1984) y Gómez (2018).

${ }^{40}$ «In tectis, modulans rutilo bona carmina rostro», v. 7 (Conflictus). 
describir el auténtico viaje migratorio que esta especie realiza cada año entre Europa y el sur del África tropical. Así, además de amenizar los campos con su canto, el cuco llena el paisaje de alegres brotes («Opto meus veniat cuculus cum germine laeto», v. 16), aleja el frío invernal («Frigora depellat, Phoebo comes almus in aevum», v. 17) y permite que se de inicio a innumerables actividades hasta entonces detenidas ( «Non veniat cuculus, generat quia forte labores», v. 19; «Haec cuculus nescit, sed perfidus ille laborat», v. 27).

Estos últimos versos requieren de un análisis más pausado. El poeta decide hacer referencia a la naturaleza trabajadora y esforzada del cuco, en primer lugar, porque su aparición coincide con el momento en que el clima invernal ha cesado sus rigores y, por lo tanto, han de dar comienzo las tareas agrícolas de la primavera. En este sentido, no existe metáfora más adecuada que la que utiliza Primavera para describir al cuco adornando los campos con verdes brotes y coloridas flores. Esto mismo se aplica a otras actividades que en la Antigüedad y el Medievo se interrumpían cuando la climatología era adversa y extrema, como la guerra, cuya reanudación el personaje de Invierno adjudica también al retorno del ave ${ }^{41}$. En segundo lugar, existe cierta literalidad en la caracterización del cuco como un animal trabajador y brioso: su estrategia reproductiva implica un gran esfuerzo, dado que debe vigilar sin pausa aquellos nidos en los que depositará sus huevos cuando llegue el momento adecuado. El personaje de Primavera, de hecho, dedica una segunda terna de versos a presentar los beneficios que acarrea el retorno del ave (vv. 28-30) para responder a los argumentos ofrecidos por Invierno. El incesante canto del cuco, que se escucha de forma persistente en las campiñas durante la primavera, participa de esta misma idea que lo identifica como un trabajador incansable. Otra vez, el poeta demuestra que escribe a partir de una fina observación de la propia realidad.

El uso del motivo literario del cuco que se realiza en el poema $D e$ cuculo es similar al que ha sido descrito para el Conflictus, dado que también fundamenta su principal entramado discursivo en la condición migratoria de esta ave. La tradición elegíaca, no obstante, se advierte vigorosa en él: de forma sintética, el De cuculo presenta el diálogo que mantienen el joven Dafnis y el anciano Menalcas, que intercambian quejas y lamentos tras la desaparición de un amigo común, al que se refieren como «el Cuco». Nuevamente, el canto amebeo se evidencia como una influencia estructural de importancia. Tal y como ha estudiado por extenso la crítica, el poema juega constantemente con esta doble significación que encierra la palabra cuco, que sirve para referirse al ave y, al mismo tiempo, al amigo que ha huido. Tiene su origen en un

${ }^{41}$ El mencionado fragmento de Hesíodo ilustra a la perfección la proximidad que siempre han mantenido el cuco y el calendario agrícola. Vid. Hes. Op. 1485-1489. 
episodio vital experimentado por el propio Alcuino de York, tal y como muestran sus epístolas conservadas ${ }^{42}$. Dicha correspondencia revela un juego ornitológico entre el poeta y algunos amigos y alumnos ${ }^{43}$. Así, el propio Alcuino de York se refiere a sí mismo como ganso, golondrina o cisne; el obispo Arne es un águila, y uno de los discípulos es conocido como «Cuco» ${ }^{44}$. La identidad de este último, según Dümmler (1879: 69) y Scott (1965: 513), se corresponde con la de un tal Dodo, estudiante al que en cierto momento dirige una misiva con un contenido muy similar al De cuculo (epístola n. ${ }^{\circ} 65$ de la edición de Dümmler). En ella se lamenta de que este lo haya abandonado en términos casi exactos a los que constan en el poema: «raptus est ab uberibus meis»; «Inimitiorque noverca»; «de paterno gremio per libidinum vortices caro rapuit $»^{45}$. También la epístola n. ${ }^{\circ} 66$ del repertorio de Dümmler (1895: 109-110) incluye una referencia al Cuco: «Aquila (Arno Episcopus) Cuculum amicum ad vitae emendationem hortatur».

De hecho, para Ebert (1878), la identidad de Dodo es el elemento que permite explicar que tanto el Conflictus como el De cuculo empleen simultáneamente al cuco como símbolo literario. Ebert considera que este discípulo de Alcuino de York fue el autor del Conflictus y, asimismo, sugiere que puede ser identificado con Angilberto (ca. 740-814), que fue pupilo aventajado de Alcuino y miembro destacado de la corte de Carlomagno. Desde luego, no parece descabellado que la máscara pastoril también forme parte del significado último del Conflictus, dado que el género bucólico la utiliza con frecuencia para ocultar identidades reales bajo la apariencia de personajes alegóricos. No parece, a pesar de ello, que su importancia sea excesiva en la interpretación de esta pieza en concreto, en tanto que los personajes principales del debate son Primavera e Invierno y no los pastores. Estos últimos no ejercen más que una función secundaria como meros espectadores y jueces. Bien distinto es el caso del De cuculo, en el que sí se detectan evidentes referencias a la vida de Alcuino de York ${ }^{46}$.

El paralelismo que se plantea en el poema entre la citada huida de Dodo y la migración anual del cuco es evidente. De hecho, este uso simbólico es muy acertado, dado que su canto se suele escuchar con suma facilidad entre los meses de abril y julio, pero se interrumpe de forma repentina con la llegada de la canícula. Su partida a África, que se produce

${ }^{42}$ Las epístolas de Alcuino de York también fueron editadas por Dümmler (1895: 1-493).

${ }^{43}$ Estas referencias se encuentran en las epístolas n. ${ }^{\text {os }} 59,146$ y 159. Cfr. Dümmler (1895: $102,235,257)$.

${ }^{44}$ Vid. Dümmler (1879: 68-69).

${ }^{45}$ «Carissimo filiolo meo, quem et sero genui et cito dimisi, nec bene ablactatus raptus est $\mathrm{ab}$ uberibus meis. Inimitiorque noverca tam tenerum de paterno gremio per libidinum vortices caro rapuit [...]» (Dümmler 1895: 107).

${ }^{46}$ Scott (1965: 517-518) identifica a Alcuino con Menalcas y a Dafnis con Arno de Salzburgo (ca. 750-821), que fue uno de sus discípulos más apreciados. 
entre agosto y septiembre, no hace sino incrementar esta sensación. La tradición ha recreado este hecho de manera habitual, tal y como evidencia el conocido refrán castellano «Al cuco, San José le da el habla, y San Pedro se la quita» (Pedrosa 2010: 36) ${ }^{47}$. Esta desaparición repentina del cuco es a la que hace referencia el De cuculo en sus versos iniciales: «Plangamus cuculum, Dafnin dulcissime, nostrum, / Quem subito rapuit saeva noverca suis» (vv. 1-2). Por lo tanto, existe una doble referencia de naturaleza real y literaria: de un lado, a la condición migratoria del ave, que desaparece siempre al fin del verano de forma súbita; del otro, a la ausencia también inesperada del Cuco, que causa una sorpresa equiparable -además de un desasosiego inconmensurable- en sus amigos Dafnis y Menalcas.

La migración a la que se enfrentan anualmente las aves es un camino repleto de peligros: una gran proporción de las que emprenden el viaje muere debido a causas diversas -agotamiento, depredación, accidentes- mientras recorren los miles de kilómetros que separan sus puntos de partida y destino (Europa y África). El poeta alude precisamente a estos riesgos cuando menciona al cuervo (Corvus corax), única alusión ornitológica adicional que existe en ambos poemas: «Si vivat, redeat, nidosque recurrat ad almos, / Nec corvus cuculum dissecet ungue fero» (vv. 19-20). Esta doble referencia entre el mundo real y el contenido poético se detecta, por lo tanto, también en este aspecto de la composición: según la perspectiva del yo poético, el Cuco se ha embarcado en una aventura tan peligrosa para él mismo como la que realiza anualmente el ave homónima, por lo que debe hacer frente a peligros equivalentes si pretende volver a los nidos nutricios (es decir, el ambiente escolar del que ha huido). No sorprende la referencia al cuervo, en tanto que es un ave que en la tradición ha quedado unida, de manera predominante, a los más funestos hechos y presagios desde antiguo ${ }^{48}$. Aunque esta ave es omnívora y posee hábitos alimenticios muy variados, es más bien carroñera y no depreda aves de la envergadura del cuco. Sin embargo, sí es habitual que sustraiga polluelos de los nidos para alimentarse: esta es la posible referencia real que se amplifica en el poema, pues el Cuco no es más que un volantón indefenso a ojos de sus amigos.

${ }^{47}$ El 19 de marzo es el día de san José en el santoral católico. El 29 de junio es el día dedicado a san Pablo y san Pedro. Por norma general, la llegada masiva del cuco a Europa se produce desde finales de marzo (Svensson 2009: 220), pero su canto no se convierte en habitual en los campos hasta llegado abril.

${ }^{48}$ Armstrong (1958: «Chapter 5. The Bird of Doom and Deluge») dedica un capítulo completo a examinar el simbolismo del cuervo en la cultura europea. Mynott (2018: 255-257) recopila los significados que adquirió esta ave en el mundo clásico. Charbonneau-Lassay (1997: 494-495, 498-500) analiza la ambigua significación simbólica que adquieren los córvidos en la tradición (especialmente en la cultura cristiana), que muchas veces son identificados con el propio demonio, pero otras se convierten en un símbolo de castidad equiparable a la tórtola (Streptopelia turtur). Recomendable es, asimismo, el completo monográfico que Sax (2019) ha dedicado al simbolismo que ha recibido el cuervo en distintas culturas humanas. 
Anteriormente me referí al cuco como un ave dotada de una significación ambigua en la tradición literaria: junto a la función simbólica que suele desempeñar como mensajero de la primavera, es frecuente su uso alegórico para hacer referencia a comportamientos cargados de connotaciones negativas, como la traición, la infidelidad o el engaño. Prueba de ello son las composiciones antes referidas de la poesía de cancionero, el Marqués de Santillana («Por un valle deleytoso») o William Shakespeare (última escena del Love's Labour's Lost), que revelan cómo esta multiplicidad simbólica también puede manifestarse simultáneamente en un mismo texto. Este planteamiento es el que se produce en el De cuculo, en el que se entrecruzan ambas ramas de la tradición: además de las referencias a la naturaleza migratoria del ave, el núcleo del poema está compuesto por las lamentaciones de Dafnis y Menalcas. Ambos personajes consideran al Cuco un auténtico renegado que les ha abandonado de forma súbita y traicionera para entregarse a oscuras tentaciones en compañía de la cruel madrastra y de $\mathrm{Baco}^{49}$.

El propósito del De cuculo es claro y se expresa de forma explícita en los versos finales: Dafnis y Menalcas pretenden que la poesía -el planto- conmueva al Cuco, donde quiera que se encuentre, y que decida finalmente volver junto a ellos: «Carmina post illum mittamus, carmina luctus, / Carmina deducunt forte, reor, cuculum» (vv. 49-50). En apariencia, es esta la última oportunidad que creen tener para recuperar a su amigo, que disfruta, gozoso, de la vida que ha encontrado entre los peligrosos remolinos de Baco (evidente alusión a los placeres propios del bullicio de la taberna, opuestos a la quietud del estudio que le ofrecían Dafnis y Menalcas) ${ }^{50}$.

El cuco fue, sin duda, una de las aves predilectas de Alcuino de York. Además de la importancia que adquiere en el De cuculo y el Conflictus, este curioso pajarillo también es mencionado como motivo literario en otras dos composiciones del poeta anglosajón, si bien no posee en ellas un protagonismo tan destacado como en los casos anteriores. Se trata

${ }^{49}$ Scott (1965: 518-520) analiza con precisión el origen de estas alusiones. La referencia que se realiza de la cruel madrastra en el segundo verso («saeva noverca») es otro eco virgiliano, inspirado en las Geórgicas: «pocula si quando saevae infecere novercae» (Verg. G. II. 128). Scott asume una interpretación similar a la segunda definición que aparece en el Diccionario de la lengua española para la voz madrastra ('madre que trata mal a sus hijos'), que se refiere precisamente al conocido refrán «la naturaleza es madrastra de los hombres» (DLE, s. v. madrastra). Así, la madrastra representa los peligros ocultos de la lujuria, natural inclinación para muchos que debe ser refrenada para no abandonar el camino de la virtud.

${ }^{50}$ Una parte de la crítica ha interpretado la poesía de Alcuino de York en clave homoerótica. Dicho deseo expresivo podría atisbarse en el verso 26 del De cuculo, cargado de emotividad («Te Dafnin iuvenis optat habere tuus»), aunque es posible que se trate, simplemente, de una muestra de efusividad; vid. Bromell (2002: 16) y Boswell (2015: 189-191). Otros críticos refutan esta hipótesis y consideran que en la obra del poeta anglosajón no hay más que una simple expresión de la amicitia medieval; vid. Frantzen (1998: 198) y Dales (2013: 228). 
de los poemas 59 («A los estudiantes de York») y 60 («A Homero») $)^{51}$ : también los dos sitúan su contenido poético en un ambiente plenamente primaveral, introducido a partir de la mención del ave. Los primeros versos de ambas composiciones aluden explícitamente al cuco:

\author{
Poema 59: \\ «Nunc cuculus ramis etiam resonavit in alis: \\ Florea versicolor pariet nune germina tellus \\ $[\ldots] »$ \\ Poema 60: \\ «Dum suetas soleat cignus servare camaenas, \\ cuculus et propios novit habere sonos \\ $[\ldots] \gg$
}

A modo de recapitulación final, conviene recordar que, a pesar de la elevada coincidencia temática existente, cada uno de los poemas analizados adquiere una identidad propia: si el tono que existe en el Conflictus es festivo y amable, el que impera en el De cuculo es más bien de amargura y desesperación. La influencia estructural del canto amebeo condiciona a ambas composiciones, que presentan a dos parejas de contendientes dialógicos (Dafnis y Menalcas; Primavera e Invierno) que se sirven simultáneamente del motivo literario del cuco con propósitos diferentes: celebrar la llegada de la primavera y lamentar la desaparición de un amigo querido. Todo ello se desarrolla en un ambiente que mezcla lo real con lo simbólico y que hunde sus raíces en la poesía bucólica virgiliana.

\title{
TEXTOS LATINOS Y TRADUCCIONES AL CASTELLANO
}

Se ofrece, a continuación, el texto latino de ambas composiciones a partir de la edición de Ernst Dümmler ${ }^{52}$. Se incluye su traducción al castellano, inédita hasta la fecha: se ha respetado la estructura del verso original latino, si bien no se ha pretendido realizar una traducción poética. Se ha respetado escrupulosamente el sentido del texto latino, al mismo tiempo que se ha tratado de mantener su naturalidad expresiva y riqueza lírica ${ }^{53}$. Por razones de homogeneidad gráfica y para facilitar la lectura del De cuculo, se ha señalado en la traducción la identidad de cada uno de los intervinientes al comienzo de cada pareja de versos.

\footnotetext{
${ }^{51}$ Ambas piezas fueron recogidas en la antología de Dümmler (1881: 273-274).

${ }^{52}$ La posterior edición de Karl P. Harrington y Jospeh Pucci utiliza el texto de Dümmler sin ningún cambio, aunque añade nuevas notas críticas. Vid. Harrington/Pucci (1997: 220-225).

${ }^{53}$ Agradezco a la profesora Teresa Jiménez Calvente la revisión que ha realizado de estas traducciones, sus consejos de interpretación, así como las lecturas propuestas para numerosos versos. Su ayuda ha sido fundamental para ofrecer una traducción adecuada de estos poemas de Alcuino de York. Cualquier posible error que exista en los textos se debe, por supuesto, a mí mismo. En adición, quisiera expresar mi gratitud con el profesor Carlos Alvar, cuyas sugerencias han contribuido a enriquecer notablemente la disposición final de ambos textos.
} 


\section{VERSUS DE CUCULO}

Texto latino (Dümmler 1881: 269-270)

Plangamus cuculum, Dafnin dulcissime, nostrum,

Quem subito rapuit saeva noverca suis.

Plangamus pariter querulosis vocibus illum,

Incipe tu senior, quaeso, Menalca prior.

[5] «Heu, cuculus nobis fuerat cantare suetus,

Quae te nunc rapuit hora nefanda tuis?

$\mathrm{Heu}$, cuculus, cuculus, qua te regione reliqui,

Infelix nobis illa dies fuerat.

Omne genus hominum, volucrum simul atque ferarum

[10] Conveniat nostrum querere nunc cuculum.

Omne genus hominum cuculum conplangat ubique,

Perditus est, cuculus, heu, perit ecce meus.

Non pereat cuculus, veniet sub tempore veris.

Et nobis veniens tarmina laeta ciet.

[15] Quis scit, si veniat; timeo, est summersus in undis,

Vorticibus raptus atque necatus aquis.

Heu mihi, si cuculum Bachus dimersit in undis,

Qui rapiet iuvenes vortice pestifero.

Si vivat, redeat, nidosque recurrat ad almos, [20] Nec corvus cuculum dissecet ungue fero.

Heu quis te, cuculus, nido rapit ecce paterno?

Heu rapuit, rapuit, nescio si venias.

Carmina si curas, cuculus, citus ecce venito,

Ecce venito, precor, ecce venito citus.

[25] Non tardare, precor, cuculus, dum currere possis,

Te Dafnin iuvenis optat habere tuus.

Tempus adest veris, cuculus modo rumpe soporem,

Te cupit, en, senior atque Menalca pater.

En tondent nostri librorum prata iuvenci,

[30] Solus abest cuculus, quis, rogo, pascit eum?

Heu, male pascit eum Bachus, reor, impius ille,

Qui sub cuncta cupit vertere corda male.

Plangite nunc cuculum, cuculum nunc plangite cuncti, Ille recessit ovans, flens redit ille, puto.

[35] Opto tamen, flentem cuculum habeamus ut illum,

Et nos plangamus cum cuculo pariter.

Plange tuos casus lacrimis, puer indite, plange:

Et casus plangunt viscera tota tuos.

Si non dura silex genuit te, plange, precamur,

[40] Te memorans ipsum plangere forte potes.

Dulcis amor nati cogit deflere parentem,

Natus ab amplexu dum rapitur subito.

Dum frater fratrem germanum perdit amatum, 
VERSOS SOBRE EL CUCO

Traducción al español

Menalcas:-Lloremos a nuestro cuco, dulcísimo Dafnis, al que de improviso se llevó la cruel madrastra con los suyos.

Dafnis: - Llorémoslo juntos con voces quejumbrosas;

tú, que eres el más añoso, empieza primero, por favor, Menalcas.

[5] Menalcas: — «Ay!, cuco, que te habías acostumbrado a cantar para nosotros, ¿qué hora fatídica te ha robado ahora de los tuyos?

Dafnis: — ¡Ay, cuco, cuco! ¿En qué región te dejé?

Aquel día fue triste para nosotros.

Menalcas: -El linaje de los hombres al completo, de las aves y los animales, [10] reúnase ahora para llorar a nuestro cuco.

Dafnis: — El linaje de los hombres al completo llora al cuco en todas partes.

Está en las últimas mi cuco, ¡ay! ¡He ahí que se ha muerto!

Menalcas: - Puede que no esté muerto el cuco, vendrá en el tiempo de la primavera. Y con su venida nos moverá a alegres cantos.

[15] Dafnis: — ¿Quién sabe si vendrá? Me temo que está hundido bajo las olas, raptado por los remolinos y ahogado en las aguas.

Menalcas: - ¡Ay de mí, si Baco ha sumergido al cuco en sus ondas, que arrastrará a los jóvenes a un remolino de destrucción!

Dafnis:- Si está vivo, que vuelva, y que retorne con rapidez a los nidos que le nutren, [20] y que el cuervo no despedace al cuco con su cruel garra.

Menalcas: — ¡Ay! ¿Quién, cuco, te raptó del nido paterno?

¡Ay, te raptó, te raptó! No sé si volverás.

Dafnis: - Si te preocupan las canciones, cuco, ¡entonces ven pronto!, ¡ven pronto, pues, te suplico!, ¡ven pronto!

[25] Menalcas: - No tardes, cuco, por favor, mientras puedas correr; tu joven Dafnis desea tenerte.

Dafnis: - La primavera ya está aquí; quiebra en seguida, cuco, el sopor, ¡vamos, el viejo padre Menalcas también te echa en falta!

Menalcas: — ¡Ea, pues!, nuestros novillos pastan en los prados de sus libros, [30] tan solo falta el cuco; ¿quién, pregunto, lo alimenta?

Dafnis: — ¡Ay, lo alimenta el impío de Baco, que desea destruir todos los corazones!

Menalcas: - Llorad ahora al cuco, todos juntos ahora llorad al cuco; él se alejó con alegría; vuelve llorando, pienso.

[35] Dafnis: - Deseo, sin embargo, que [pronto] tengamos al lacrimoso cuco y que nosotros lloremos con el cuco al mismo tiempo.

Menalcas: - Llora tus desgracias con lágrimas, ilustre muchacho, llora: también todas tus entrañas lloran tus desgracias.

Dafnis: - Si no te engendró una insensible roca, llora, te rogamos; [40] recordando quién eres, quizás puedes llorar.

Menalcas: -El dulce amor por un hijo fuerza al padre a llorar cuando el hijo es sustraído súbitamente de sus brazos.

Dafnis:-Cuando el hermano pierde a su amado hermano carnal, 
Quid nisi iam faciat, semper et ipse fleat.

[45] Tres olim fuimus, iunxit quos spiritus unus,

Vix duo nunc pariter, tertius ille fugit.

Heu fugiet, fugiet, planctus quapropter amarus

Nunc nobis restat, carus abit cuculus.

Carmina post illum mittamus, carmina luctus,

[50] Carmina deducunt forte, reor, cuculum.

Sis semper felix utinam, quocumque recedas,

Sis memor et nostri semper ubique vale».

\section{Conflictus Veris et HIEMIS}

Texto latino (Dümmler 1881: 270-272)

Conveniunt subito cuncti de montibus altis

Pastores pecudum vernali luce sub umbra

Arborea, pariter laetas celebrare Camenas.

Adfuit et iuvenis Dafnis seniorque Palemon;

[5] Omnes hi cuculo laudes cantare parabant.

Ver quoque florigero succinctus stemmate venit,

Frigida venit Hiems, rigidis hirsuta capillis.

His certamen erat cuculi de carmine grande.

Ver prior adlusit ternos modulamine versus:

[10] Ver: — «Opto meus veniat cuculus, carissimus ales.

Omnibus iste solet fieri gratissimus hospes

In tectis, modulans rutilo bona carmina rostro».

Hiems: Tum glacialis hiems respondit voce severa:

«Non veniat cuculus, nigris sed dormiat antris.

[15] Iste famem secum semper portare suescit».

Ver: - «Opto meus veniat cuculus cum germine laeto, Frigora depellat, Phoebo comes almus in aevum.

Phoebus amat cuculum crescenti luce serena».

Hiems: - «Non veniat cuculus, generat quia forte labores, [20] Proelia congeminat, requiem disiungit amatam, Omnia disturbat: pelagi terraeque laborant».

Ver: — «Quid tu, tarda Hiems, cuculo convitia cantas?

Qui torpore gravi tenebrosis tectus in antris

Post epulas Veneris, post stulti pocula Bacchi». 
¡qué, si no, puede hacer más que llorar sin cesar!

[45] Menalcas: - Tres fuimos una vez, a los que unió un único espíritu, ahora apenas somos dos, el tercero ha huido.

Dafnis: — ¡Ay, huirá, huirá! Llanto amargo, por ello, nos queda ahora; el querido cuco se aleja.

Menalcas: - Enviemos tras él poemas, poemas de dolor; [50] estos poemas, creo, tal vez traigan de vuelta al cuco.

Dafnis: - Ojalá que seas siempre feliz, donde quiera que te escondas, y que te acuerdes de nosotros por siempre y en todas partes. ¡Adiós!

\section{La Disputa entre la PrimaVera y el INVIERNo}

Traducción al español

Con rapidez se reunieron desde los altos montes todos

los pastores de los rebaños a la luz de la primavera, bajo la sombra de los árboles, para celebrar juntos a las alegres Camenas.

Allí estaban el joven Dafne y el mayor Palemón:

[5] todos ellos se disponían a cantar alabanzas al cuco.

También llegó la Primavera, ceñida con una guirnalda florida; llegó el frío Invierno, hirsuto de cabellos helados.

Hubo entre ellos una gran disputa sobre el canto del cuco.

La Primavera entonó primero una terna de versos con musicalidad:

[10] Primavera: - Deseo que venga mi cuco, queridísima ave.

Suele ser el más grato huésped en todas las casas, modulando agradables canciones con su pico brillante.

Entonces, el helado Invierno respondió con voz severa:

Invierno: - Que no venga el cuco, que duerma en negras cavernas; [15] ese acostumbra siempre a traer el hambre consigo.

Primavera: -Deseo que con los alegres brotes llegue mi cuco, almo compañero de Febo en esta estación, y que expulse el frío. Febo estima al cuco en la serena luz creciente.

Invierno: - Que no venga el cuco, porque quizás acaree dolores: [20] redobla las batallas, rompe el amado descanso, todo lo altera; los mares y las tierras sufren.

Primavera: — ¿Por qué tú, perezoso Invierno, cantas escarnios al cuco? Tú, que con pesado torpor, te escondes en oscuras cavernas tras los banquetes de Venus, tras las copas del loco Baco. 
[25] Hiems: — «Sunt mihi divitiae, sunt et convivia laeta, Est requies dulcis, calidus est ignis in aede.

Haec cuculus nescit, sed perfidus ille laborat».

Ver: — «Ore feret flores cuculus et mella ministrat, Aedificatque domus, placidas et navigat undas, [30] Et generat soboles, laetos et vestiet agros».

Hiems: - «Haec inimica mihi sunt, quae tibi laeta videntur. Sed placet optatas gazas numerare per arcas Et gaudere cibis simul et requiescere semper».

Ver: — «Quis tibi, tarda Hiems, semper dormire parata, [35] Divitias cumulat, gazas vel congregat ullas, Si ver vel aestas ante tibi nulla laborant?»

Hiems: — «Vera refers: illi, quoniam mihi multa laborant, Sunt etiam servi nostra ditione subacti, Iam mihi servantes domino, quaecumque laborant?»

[40] Ver: — «Non illis dominus, sed pauper inopsque superbus, $\mathrm{Nec}$ te iam poteris per te tu pascere tantum,

Ni tibi qui veniet cuculus alimonia praestet».

Palemon:

Tum respondit ovans sublimi e sede Palemon Et Dafnis pariter, pastorum et turba piorum: [45] «Desine plura, Hiems; rerum tu prodigus, atrox. Et veniat cuculus, pastorum dulcis amicus. Collibus in nostris erumpant germina laeta, Pascua sint pecori, requies et dulcis in arvis, Et virides rami praestent umbracula fessis, [50] Uberibus plenis veniantque ad mulctra capellae, Et volucres varia Phoebum sub voce salutent. Quapropter citius cuculus nunc ecce venito! Tu iam dulcis amor, cunctis gratissimus hospes: Omnia te expectant, pelagus tellusque polusque, [55] Salve, dulce decus, cuculus, per saecula salve!» 
[25] Invierno: - Tengo riquezas, y celebro alegres banquetes, el reposo es dulce, cálido es el fuego en el hogar.

Esto lo ignora el cuco; en cambio él, pérfido, pasa fatigas.

Primavera: - Con la boca lleva flores el cuco, y suministra mieles, y construye hogares, y navega calmadas aguas, [30] y engendra prole y adorna los campos con alegría.

Invierno: - Me son contrarias estas cosas que te parecen alegres. Más bien me gusta contar por cofres los deseados tesoros $\mathrm{y}$, al mismo tiempo, disfrutar de la comida y descansar siempre.

Primavera: — ¿Quién, perezoso Invierno, siempre dispuesto a dormir, [35] te acumula riquezas, o reúne algunos tesoros, si la Primavera o el Verano no trabajan antes para ti?

Invierno: — Verdad dices: porque ellos trabajan mucho para mí, incluso son siervos míos sometidos bajo mi jurisdicción, preservando para mí que soy su señor el fruto entero de su trabajo.

[40] Primavera: — No eres su señor, sino un soberbio pobre y sin recursos. Ni siquiera serás capaz de satisfacer tus propias necesidades si no es por el cuco que viene y te proporciona alimentos.

Entonces respondió Palemón, aplaudiendo desde su alto asiento, y también Dafne y la multitud de piadosos pastores.

[45] Palemón: — «No hables más, Invierno: derrochador, cruel. $\mathrm{Y}$ venga el cuco, dulce amigo de los pastores; estallen los abundantes brotes en nuestras colinas; haya pastos para el rebaño, suave sosiego en los campos. $\mathrm{Y}$ verdes ramas proporcionen sombras a los cansados, [50] y vengan con las ubres llenas las cabras al ordeño, y saluden los pájaros con cantos variados a Febo.

Por ello, ¡ven más deprisa, cuco!

Tú, que eres ya dulce amor, el huésped más grato para todos, todo te espera: el mar y la tierra y el cielo. [55] ¡Salve, dulce belleza!, ¡salve, por siempre, cuco! 
REFERENCIAS BIBLIOGRÁFICAS

Abella, Ignacio (2017), Aves familiares. Vida y leyenda. Bilbao: Libros del Jata.

Armstrong, Edward A. (1958), The Folklore of Birds. London: Collins.

Barrio Sanz, Encarnación del, Ignacio García Arribas, Ana María Moure Casas, Luis Alfonso Hernández Miguel y María Luisa Arribas Hernáez (eds. y trads.) (2003), Plinio el Viejo, Historia Natural. Libros VII-XI. Madrid: Gredos.

BERnis, Francisco (1995), Diccionario de nombres vernáculos de aves. Madrid: Gredos.

Boswell, John (2015), Christianity, Social Tolerance and Homosexuality. Gay People in Western Europe from the Beginning of the Christian Era to the Fourteenth Century. Chicago/London: The University of Chicago Press.

Bromell, John (2002), «Alcuin», en Robert Aldrich y Garry Wotherspoon (eds.), Who's who in Gay and Lesbian History: From Antiquity to World War II. London/New York: Routledge, pp. 15-16.

Bulst, Walther (1955), «Alchvvines Ecloga de Cvcvlo», Zeitschrift für deutsches Altertum und deutsche Literatur, 86/3, pp. 193-196.

CARrara, Enrico (1909), La poesia pastorale. Milano: Casa Editrice Dottor Francesco Vallardi.

CAstillo, Carmen (1973), «La composición del "Conflictus veris et hiemis” atribuido a Alcuino», Cuadernos de Filología Clásica, 5, pp. 53-61.

Charbonneau-Lassay, Louis (1997), El bestiario de Cristo. El simbolismo animal en la Antigüedad y la Edad Media. Barcelona: José J. de Olañeta, Editor.

Clavería NADAL, Gloria (1992), «Reflexiones en torno a la historia lexicográfica de las voces cuclillo y curruca», Anuario de Estudios Filológicos, 15, pp. 39-54.

Combet, Louis (ed.) (2000), Gonzalo Correas, Vocabulario de refranes y frases proverbiales (1627). Revisión de Robert James y Maïté MirAndreu. Madrid: Castalia.

DALes, Douglas (2013), Alcuin: Theology and Thought. Cambridge: James Clarke \& Co.

DíAz-Mas, Paloma (1994), Romancero. Barcelona: Editorial Crítica.

DüMMLER, E. (1879), «Über die gedichte De cuculo», Zeitschrift für deutsches Altertum und deutsche Literatur, 23, pp. 67-71.

DüMmLER, Ernst (1881), Monumenta Germaniae Historica. Poetarum latinorum Medii Aevi. Tomus I: Vol. I. Berlin: Weidmannos.

DüMmLER, Ernst (1895), Monumenta Germaniae Historica. Epistolarum Tomus IV. Karolini Aevi II. Berlin: Weidmannos. 
Dutton, Brian y Joaquín González Cuenca (eds.) (1993), Cancionero de Juan Alfonso de Baena. Madrid: Visor Libros.

EBert, Adolf (1878), «Naso, Angilbert und der Conflictus Veris et Hiemis», Zeitschrift für deutsches Altertum und deutsche Literatur, 22, pp. 328-335.

Ernout, Alfred y Alfred MeILlet (2001), Dictionnaire étymologique de la langue latine. Histoire des mots. Adiciones y correciones de Jacques André. Paris: Klincksieck.

Escudero MARTínez, Carmen (1984), «El canto amebeo clásico en la literatura española», en Simposio Virgiliano: conmemorativo del Bimilenario de la muerte de Virgilio. Murcia: Universidad de Murcia, pp. 255-264.

Frantzen, Allen J. (1998), Before the Closet. Same-sex Love from Beowulf to Angels in America. Chicago/London: The University of Chicago Press.

GArcía Romero, Fernando (2008), «Una golondrina no hace primavera», Paremia, 17, pp. 131-142.

GómEz, Jesús (2018), «Cantos amebeos: de Garcilaso a Góngora», $R e$ vista de Literatura, 80/160, pp. 361-384.

Gómez Moreno, Ángel y Maximiliam P. A. M. Kerkhof (eds.) (1988), Íñigo López de Mendoza, Marqués de Santillana, Obras completas. Barcelona: Planeta.

GonzÁlez CuencA, Joaquín (ed.) (1996), Cancionero musical de Palacio. Madrid: Visor Libros.

GonzÁlez-HabA, Mercedes (ed. y trad.) (1992), Plauto, Comedias I. Anfitrión. La comedia de los asnos. La comedia de la olla. Las dos Báquides. Los cautivos. Cásina. Madrid: Gredos.

Guadalajara Salmerón, Sergio (2020), «Ruiseñoles (Ruiseñor)», en Carlos Alvar Ezquerra (ed.), Gran Enciclopedia Cervantina. Volumen XI. Quijote de La Mancha-Sandoval y Rojas. Alcalá de Henares: Universidad de Alcalá, pp. 11392-11393.

GubernATIS, Angelo de (2002), Mitología zoológica. Las leyendas animales. Los animales del aire. Palma de Mallorca: José J. de Olañeta, Editor.

Harrington, Karl Pomeroy y Joseph Pucci (1997), Medieval Latin (2. ed.). Chicago/London: The University of Chicago Press.

Haskell, David George (2019), En un metro de bosque. Un año observando la naturaleza. Madrid: Turner Noema.

Herrero Ingelmo, María Cruz (ed. y trad.) (1994), Pausanias, Descripción de Grecia. Libros I-II. Madrid: Gredos.

Hornblower, S., A. SPAwForth y E. EIDINow (2012), The Oxford Classical Dictionary. Fourth Edition. Oxford: Oxford University Press.

KIM, Megan I. (1992), «A Parrot and Piety: Alcuin's Nightingale and Ovid's “Amores” 2.6», Latomus, 51/4, pp. 881-891. 
LiDA DE Malkiel, María Rosa (1975), «El ruiseñor de las Geórgicas y su influencia en la lírica española de la Edad de Oro», en M. ${ }^{a}$ Rosa Lida de Malkiel, La tradición clásica en España. Barcelona: Ariel, pp. 100-117.

Macía ApAricio, Luis Miguel (ed. y trad.) (2007), Aristófanes, Comedias II. Las nubes. Las avispas. La paz. Los pájaros. Madrid: Gredos.

McEnerney, John I. (1981), «Alcuin, Carmen 58», Mittellateinisches Jahrbuch, 16, pp. 35-42.

Merriam-Webster (2020), Merriam-Webster's Collegiate Dictionary [versión digital]. En línea: <https://www.merriam-webster.com/> [consulta: 18/02/2021].

Mynott, Jeremy (2018), Birds in the Ancient World. Oxford: Oxford University Press.

NoRmand, Hélène (2015), Les rapaces dans les mondes grec et romain. Catégorisation, représentations culturelles et pratiques. Bordeaux: Ausonius.

Oroz Reta, José y Manuel-A. Marcos CAsquero (eds. y trads.) (2004), Isidoro de Sevilla, Etimologías. Madrid: Biblioteca de Autores Cristianos.

PAllí Bonet, Julio (ed. y trad.) (1992), Aristóteles, Investigación sobre los animales. Introducción de Carlos García Gual. Madrid: Gredos.

Pedrosa, José Manuel (2001), «Los augurios del cuco: versiones hispánicas y paneuropeas», Quaderni di Semantica, 22, pp. 93-104.

Pedrosa, José Manuel (2010), «Paremias, creencias, ritos. Los augurios del cuco», en José Enrique Gargallo, Paremiología romance. Los refranes meteorológicos. Barcelona: Universitat de Barcelona, pp. 33-49.

PÉrez de CASTRO, José Luis (1974), «El cuclillo en la tradición asturiana», en II Congreso Nacional de artes y costumbres populares, 1971. Zaragoza: Institución «Fernando el Católico», pp. 185-211.

Pujante, Ángel-Luis (ed.) y Ángel-Luis Pujante, Salvador Oliva, y Alfredo Michel ModenEssi (trads.) (2012), William Shakespeare, Comedias y tragicomedias. Teatro Completo II [Libro electrónico]. Madrid: Espasa.

Raby, Frederic J. (1957), A History of Secular Latin Poetry in the Middle Ages (Vol. 1). Oxford: Clarendon Press.

Rodríguez Adrados, Francisco (1980), «La fábula de la golondrina de Grecia a la India y la Edad Media», Emerita, 48/2, pp. 185-208.

RodríGuEz Adrados, Francisco (1982), «Más sobre la fábula de la golondrina», Emerita, 50/1, pp. 75-80.

SAX, Boria (2019), Cuervo. Naturaleza, historia y simbolismo. Madrid: Siruela.

ScotT, Peter Dale (1965), «Alcuin's "Versus de Cuculo": The Vision of Pastoral Friendship», Studies in Philology, 62/4, pp. 510-530. 
SEO/BIRDLIFE (2020), «Golondrina común», Guía de aves [versión digital]. En línea: $<$ https://www.seo.org/ave/golondrina-comun/> [consulta: 07/01/2021].

Svensson, Lars (2009), Guía de aves. España, Europa y región mediterránea (Segunda edición). Barcelona: Ediciones Omega.

VAZ DA Silva, Francisco (2006), «Sexual Horns: The Anatomy and Metaphysics of Cuckoldry in European Folklore», Comparative Studies in Society and History, 48/2, pp. 396-418.

ZoGG, Fabian (2017), «Palaemon and Daphnis in a Medieval Poem: The Vergilian Challenge of the Conflictus Veris et Hiemis», Vergilius, 63, pp. 125-140.

Recibido: $13 / 05 / 2021$

Aceptado: 30/07/2021 
$\cos$

\author{
El MOTIVO LITERARIO DEL CUCO (CUCULUS CANORUS) \\ EN LA LITERATURA EUROPEA: ANÁLISIS Y TRADUCCIÓN \\ AL CASTELLANO DEL CONFLICTUS VERIS ET HIEMIS Y \\ EL VeRSUS DE CUCULO (AlCUINO DE YoRK)
}

\begin{abstract}
RESUMEN: El cuco común (Cuculus canorus) posee diversas significaciones simbólicas en la tradición cultural europea. Entre ellas, quizás la más frecuente es la que describe a esta ave como heraldo de la primavera. Este artículo presenta un estudio comparado de la simbología asociada al cuco en la literatura clásica y las letras castellanas. Todo ello permitirá analizar la utilización alegórica de esta ave en dos de las composiciones más conocidas de Alcuino de York (el Versus de cuculo y el Conflictus Veris et Hiemis), en las que ocupa una posición central. Se ofrece, asimismo, la primera traducción al castellano de ambos poemas.
\end{abstract}

Palabras Clave: Simbología ornitológica. Alcuino de York. Cancionero. Cuco. Virgilio. Literatura de debate.

\title{
THE LITERARY MOTIF OF THE CUCKOO (CUCULUS CANORUS) IN THE EUROPEAN LITERATURE: ANALYSIS AND TRANSLATION INTO SPANISH OF THE CONFLICTUS VERIS ET HIEMIS AND THE VERSUS DE CUCULO (ALCUIN OF YORK)
}

AbSTRACT: The common cuckoo (Cuculus canorus) has several symbolic meanings in European cultural tradition. Perhaps, the most common of these is the one that describes this bird as the harbinger of spring. This article presents a comparative study of the symbolism associated with the cuckoo in classical literature and Castilian letters. This will allow to analyse the allegorical use of this bird in two of the best-known compositions by Alcuin of York (the Versus de cuculo and the Conflictus Veris et Hiemis), in which it occupies a central position. The first translation into Spanish of both poems is also offered.

KEYwORDs: Ornithological symbology. Alcuin of York. Cuckoo. Virgil. Debate Literature. 